\title{
Prognostic value of platelet-to-lymphocyte ratio in pancreatic cancer: a comprehensive meta-analysis of 17 cohort studies
}

This article was published in the following Dove Press journal:

OncoTargets and Therapy

Yongping Zhou'
Sijin Cheng

Abdel Hamid Fathy ${ }^{2}$

Haixin Qian ${ }^{3}$

Yongzhao Zhao ${ }^{1,2}$

'Department of Hepatobiliary, Wuxi Second Hospital, Nanjing Medical University, Wuxi, China; ${ }^{2}$ Tongji University School of Medicine, Shanghai, China; ${ }^{3}$ Department of Hepatobiliary, The First Affiliated Hospital of Soochow University, Suzhou, Jiangsu, China
Correspondence: Yongzhao Zhao Department of Hepatobiliary, Wuxi Second Hospital, Nanjing Medical University, No. 68 Zhongshan Road, 214002 Wuxi, China

Email yongzhao_zhao@I63.com

Haixin Qian

Department of Hepatobiliary, The First Affiliated Hospital of Soochow University, No 899, Pinghai Road, Suzhou 215000, Jiangsu, China

Tel +86 I39 I5550000

Email qianhaixin I@hotmail.com
Background and aims: Several studies were conducted to explore the prognostic value of platelet-to-lymphocyte ratio (PLR) in pancreatic cancer and have reported contradictory results. This study aims to summarize the prognostic role of PLR in pancreatic cancer.

Materials and methods: Embase, PubMed and Cochrane Library were completely searched. The cohort studies focusing on the prognostic role of PLR in pancreatic cancer were eligible. The overall survival (OS) and progression-free survival (PFS) were analyzed.

Results: Fifteen papers containing 17 cohort studies with pancreatic cancer were identified. The results showed patients that with low PLR might have longer OS when compared to the patients with high PLR (hazard ratio=1.28, 95\% CI=1.17-1.40, $P<0.00001 ; I^{2}=42 \%$ ). Similar results were observed in the subgroup analyses of OS, which was based on the analysis model, ethnicity, sample size and cut-off value. Further analyses based on the adjusted potential confounders were conducted, including CA199, neutrophil-to-lymphocyte ratio, modified Glasgow Prognostic Score, albumin, C-reactive protein, Eastern Cooperative Oncology Group, stage, tumor size, nodal involvement, tumor differentiation, margin status, age and gender, which confirmed that low PLR was a protective factor in pancreatic cancer. In addition, low PLR was significantly associated with longer PFS when compared to high PLR in pancreatic cancer (hazard ratio=1.27, 95\% CI=1.03-1.57, $\left.P=0.03 ; I^{2}=33 \%\right)$.

Conclusion: In conclusion, it was found that high PLR is an unfavorable predictor of OS and PFS in patients with pancreatic cancer, and PLR is a promising prognostic biomarker for pancreatic cancer.

Keywords: platelet-to-lymphocyte ratio, pancreatic cancer, prognostic, progression-free survival, overall survival, biomarker

\section{Introduction}

It was estimated that 53,670 cases would be newly diagnosed with pancreatic cancer and 43,090 cases would die from pancreatic cancer in the USA in 2017. ${ }^{1}$ Although great development of the diagnosis and treatment of pancreatic cancer has been made in recent years, the prognosis of patients with pancreatic cancer remains disappointing. ${ }^{2,3}$ In 2016, there were an estimated 53,070 patients newly diagnosed with pancreatic cancer and an estimated 41,780 deaths from pancreatic cancer in the USA. ${ }^{4}$

In view of the poor prognosis outcome of patients with various cancers, more and more attention was paid to explore the predictive factors of cancers..$^{5-8}$ Regarding pancreatic cancer, several factors might be involved in the prognosis of patients, including mRNA, protein, clinical index and so on. ${ }^{9-12}$ 
In recent years, several studies have reported that inflammatory pathways might play an important role in the tumorigenesis and metastasis. ${ }^{13-16}$ Meanwhile, inflammatory biomarkers are expected to be a prognostic index of pancreatic cancer, including neutrophil-to-lymphocyte ratio (NLR), C-reactive protein (CRP), platelet-to-lymphocyte ratio (PLR) and so on. ${ }^{17-19}$ Yang et al performed a meta-analysis and found that high peripheral blood PLR suggested a poor prognosis for patients with pancreatic cancer. ${ }^{19}$ However, there was no consistent conclusion on the role of PLR in pancreatic cancer. Kishi et al analyzed 65 patients with pancreatic cancer and drew the conclusion that PLR was not associated with the prognosis of these patients. ${ }^{20}$ Nevertheless, other researchers focusing on pancreatic cancer found opposite results, which indicated that patients with low PLR might have longer overall survival (OS) when compared to the patients with high PLR. ${ }^{20-22}$ On account of these controversies, we performed this meta-analysis to explore the prognostic value of PLR in pancreatic cancer.

\section{Materials and methods Literature search strategy}

The Cochrane Library, PubMed and Embase database were comprehensively searched up to May 2, 2017. The search terms included "pancreatic neoplasm", "pancreatic cancer", "PLR", "platelet-to-lymphocyte ratio", "platelet lymphocyte ratio" and "platelet-lymphocyte ratio". The relevant conference papers were also carefully assessed. All the retrieved papers were carefully checked. After scanning the abstracts or titles, the distinctly irrelevant articles were excluded. For the remaining papers, the full text was carefully reviewed.

\section{Inclusion criteria}

The study would be included into this meta-analysis if it met all the following criteria: 1) cohort study; 2) focusing on the prognostic value of PLR in pancreatic cancer; 3) enough data to obtain the hazard ratio (HR) for OS, along with their 95\% CIs or $P$-values and 4) published in English.

\section{Exclusion criteria}

The exclusion criteria were as follows: 1) comments, reviews, case reports and expert opinions; 2) data deficiencies of the HR; 3) not focusing on the prognostic value of PLR in pancreatic cancer; 4) lacking key information for further analysis; 5) duplicate publications; 6) reporting the overlapping data and 7) non-human research.

\section{Data extraction}

Two investigators evaluated and extracted the data independently. For each included study, the following data were abstracted: the first author, year of publication, country of the study, ethnicity, number of patients, percentage of males, cut-off value, survival outcomes and analysis model. It should be noted that patients in each original study were divided into two groups based on the cut-off value of PLR: high PLR group and low PLR group. The HRs of prognostic outcomes obtained directly or indirectly from the published articles were integrated in the meta-analysis according to the study conducted by Tierney et al. ${ }^{23}$ If the HR was assessed with both multivariate analysis and univariate analysis, the results of multivariate analysis were applied in the current study. The quality of the included studies was assessed using the Newcastle-Ottawa Scale (NOS). Also, studies with NOS score $\geq 6$ were considered to be of high quality. Any other disputes were discussed with the third investigator.

\section{Statistical analysis}

The main results of this meta-analysis were analyzed by Review Manager Version 5.3 software. The prognosis outcomes were assessed using the HR, along with the corresponding $95 \% \mathrm{CI}$ or $P$-values. The main prognostic outcome was the OS. Cochran's Q test and Higgins $I^{2}$ were applied to evaluate the heterogeneity among included studies. Heterogeneity should be considered if $I^{2}>50 \%$, and the random-effect model was applied; if not, the fixed-effect model was applied. In addition, to explore the publication bias, the funnel plot was drawn using Review Manager Version 5.3 software. To validate the credibility of outcomes in this meta-analysis, the sensitivity analysis was performed using Stata 12.0. Nonetheless, the subgroup analysis was carried out to further explore the association between the PLR and prognosis of patients with pancreatic cancer. The difference was considered to be statistically significant when the $P$-value was $<0.05$.

\section{Results}

\section{Literature search}

As shown in Figure 1, the literature search process is summarized in a flow diagram according to Preferred Reporting Items for Systematic reviews and Meta-analyses (PRISMA). ${ }^{24}$ One hundred seventy-one papers were initially retrieved from the Cochrane Library, PubMed and Embase database. One hundred thirty-six papers remained after duplicates were removed. For the remaining 136 papers, 112 papers with significantly diverse topics were directly excluded by 


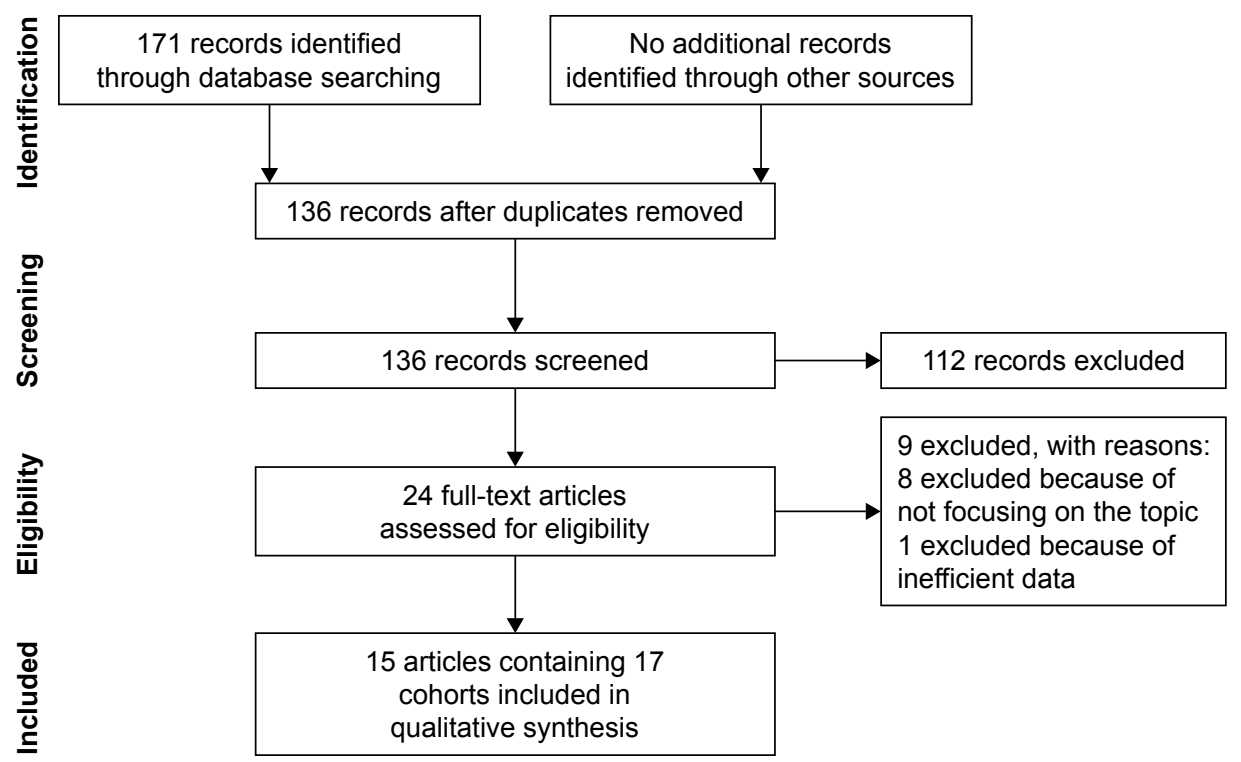

Figure I Flow diagram of the study selection process.

scanning the titles or abstracts. Among the rest of the papers, eight papers were excluded for not focusing on the topic and one paper was excluded for inefficient data. Therefore, 15 papers containing 17 cohort studies were finally included in this meta-analysis. ${ }^{20-22,25-36}$

\section{Characteristics of included studies}

The clinical details of the included studies are presented in Table 1. Regarding the 17 included cohort studies, 5 were performed in China, ${ }^{30,32,34,36} 5$ in Japan, ${ }^{20,21,26,28,35} 2$ in USA, ${ }^{22,25}$ 2 in Austria, ${ }^{33} 1$ in Australia, ${ }^{31} 1$ in Singapore ${ }^{27}$ and 1 in South Korea. ${ }^{29}$ Besides, sample size of the included cohort studies varied from 37 to 440 . As for the gender information in the included studies, the percentage of males among the cohort studies varied from $39.5 \%$ to $88.8 \%$. As for clinical outcomes, all the included cohort studies reported the OS, ${ }^{20-22,25-36}$ two studies reported the disease-free survival (DFS), ${ }^{20,21}$ one study presented the recurrence-free survival (RFS) ${ }^{22}$ and one study

Table I Main information of the included studies in the meta-analysis

\begin{tabular}{|c|c|c|c|c|c|c|c|c|c|c|}
\hline Study & Country & Ethnicity & $\begin{array}{l}\text { Patients } \\
\text { (n) }\end{array}$ & $\begin{array}{l}\text { Male } \\
\text { n (\%) }\end{array}$ & Age (years) & Outcome & Analysis & $\begin{array}{l}\text { Cut-off } \\
\text { value }\end{array}$ & Therapy & NOS \\
\hline Wang et al $2012^{34}$ & China & Asian & 177 & $120(67.8)$ & $<65.0$ (70.1\%) & OS & $U$ & 300 & NA & 7 \\
\hline Stotz et al $2013^{33}(\mathrm{I})$ & Austria & Caucasian & 261 & $103(39.5)$ & $<65.0(42.5 \%)$ & OS & $\mathrm{U}$ & 150 & NA & 6 \\
\hline Stotz et al $2013^{33}(2)$ & Austria & Caucasian & 110 & 51 (46.4) & $<65.0(50.0 \%)$ & OS & $\mathrm{U}$ & 150 & Surgery & 6 \\
\hline Martin et al $2014^{31}$ & Australia & Caucasian & 124 & $66(53.2)$ & $68.5(35-90)$ & OS & $M$ & 200 & NA & 7 \\
\hline Qi et al $2015^{32}$ & China & Asian & 211 & $134(63.5)$ & $<60.0(75.4 \%)$ & OS & $M$ & 126 & NA & 7 \\
\hline Goh et al $2015^{27}$ & Singapore & Asian & 120 & $49(40.8)$ & $60.5(24-84)$ & OS & $M$ & 208.1 & NA & 8 \\
\hline Inoue et al $2015^{28}$ & Japan & Asian & 440 & $249(56.6)$ & $67.0(32-88)$ & OS & $\mathrm{U}$ & 150 & NA & 6 \\
\hline Kishi et al $2015^{20}$ & Japan & Asian & 65 & $39(60.0)$ & $65.0(35-85)$ & OS, DFS & $\mathrm{U}$ & 150 & Chemoradiotherapy & 7 \\
\hline Shirai et al $2015^{21}$ & Japan & Asian & $13 \mid$ & $81(61.8)$ & $66.5 \pm 10.2^{\mathrm{a}}$ & OS, DFS & $M$ & 150 & Surgery & 6 \\
\hline Spolverato et al $2015^{22}$ & USA & Caucasian & 420 & $208(49.5)$ & NA & OS, RFS & $M$ & 190 & Surgery & 8 \\
\hline Alagappan et al $2016^{25}$ & USA & Caucasian & 208 & $109(52.4)$ & $75.2(65.9-86.1)$ & OS & 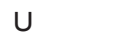 & 200 & Radiotherapy & 7 \\
\hline Asari et al $2016^{26}$ & Japan & Asian & 37 & $20(54.0)$ & $<70.0(62.0 \%)$ & OS & $M$ & 225 & Surgery & 6 \\
\hline Lee et al $2016^{29}$ & South Korea & Asian & 82 & $49(60.0)$ & $63.5 \pm 10.7^{a}$ & OS, PFS & $\mathrm{U}$ & 150 & Chemotherapy & 8 \\
\hline Watanabe et al $2016^{35}$ & Japan & Asian & 46 & $26(56.5)$ & NA & OS & $M$ & 200 & Surgery & 6 \\
\hline Liu et al $2017^{30}$ & China & Asian & 386 & $238(61.7)$ & $<65.0(64.2 \%)$ & OS & $\mathrm{U}$ & 165.5 & NA & 6 \\
\hline Yu et al $2017^{36}(1)$ & China & Asian & 139 & $83(59.7)$ & $<60.0(38.8 \%)$ & OS & $\mathrm{U}$ & 154 & Chemotherapy & 7 \\
\hline Yu et al $2017^{36}(2)$ & China & Asian & 225 & $146(64.9)$ & $<60.0(34.7 \%)$ & OS & U & 154 & Chemotherapy & 6 \\
\hline
\end{tabular}

Notes: (I) cohort I; (2) cohort II. Data presented as range unless otherwise indicated. aData presented as mean \pm SD.

Abbreviations: DFS, disease-free survival; M, multivariate analysis; NA, not available; NOS, Newcastle-Ottawa scale; OS, overall survival; PFS, progression-free survival; RFS, recurrence-free survival; $U$, univariate analysis. 
covered the progression-free survival (PFS). ${ }^{29}$ Moreover, the OS of 10 cohort studies was assessed with univariate analysis, ${ }^{20,25,28-30,33,34,36}$ however, the other studies evaluated it with multivariate analysis. ${ }^{21,22,26,27,31,32,35}$ Besides, the NOS score of each included study was $\geq 6$, which meant that the included studies were of relatively high quality. Regarding the seven studies assessed with multivariate analysis, the main adjusted potential confounders included CA199, NLR, modified Glasgow Prognostic Score (mGPS), albumin, CRP, Eastern Cooperative Oncology Group (ECOG), stage, tumor size, nodal involvement, tumor differentiation, margin status, age and gender, and the details are listed in Table S1.

\section{The meta-analysis of OS}

All the included studies covered the OS of patients with pancreatic cancer. Therefore, 17 cohort studies were finally gathered into the meta-analysis of OS. As shown in Figure 2, in view of low heterogeneity $\left(I^{2}=42 \%\right)$, fixed-effect model was used. And the results indicated that there was statistically significant relationship between the PLR and prognosis of patients with pancreatic cancer, and patients with low PLR might have longer OS when compared to the patients with high PLR $(\mathrm{HR}=1.28,95 \% \mathrm{CI}=1.17-1.40, P<0.00001)$. Furthermore, funnel plot was conducted to explore the bias among the included studies, and the results demonstrated that no obvious publication bias was detected (Figure 3). Furthermore, sensitivity analysis conducted by Stata 12.0 confirmed the robustness of the results (Figure S1).

To further explore the prognostic value of PLR in pancreatic cancer, subgroup analyses were performed based on the analysis model, ethnicity, sample size and cut-off value. The main results were presented in Table 2 . In terms of analysis model, when only the studies with multivariate analysis were included into the meta-analysis, significant association between the PLR and OS was observed, with low heterogeneity $(\mathrm{HR}=1.76,95 \% \mathrm{CI}=1.45-2.14$, $\left.P<0.00001 ; I^{2}=9 \%\right)$. Similarly, when only considering the studies with univariate analysis, obvious correlation was detected between the PLR and prognosis of pancreatic cancer $\left(\mathrm{HR}=1.18,95 \% \mathrm{CI}=1.07-1.30, P=0.001 ; I^{2}=0 \%\right)$. Subgroup analyses by ethnicity revealed that negative predictor of high PLR for OS was found both in Asian cases $\left(\mathrm{HR}=1.35,95 \% \mathrm{CI}=1.14-1.61, P=0.0006 ; I^{2}=52 \%\right)$ and in Caucasian populations $(\mathrm{HR}=1.25,95 \% \mathrm{CI}=1.08-1.45$, $P=0.004 ; I^{2}=17 \%$ ). Regarding sample size, distinct association between the PLR and OS was detected not only when the sample size $\leq 150(\mathrm{HR}=1.49,95 \% \mathrm{CI}=1.14-1.94, P=0.003$; $\left.I^{2}=52 \%\right)$ but also when the sample size $>150(\mathrm{HR}=1.26$, 95\% CI=1.11-1.42, $P=0.0003 ; I^{2}=31 \%$ ). Additionally, considering different cut-off values, PLR was a negative prognostic biomarker for the cut-off value $\leq 150(\mathrm{HR}=1.19$, 95\% $\left.\mathrm{CI}=1.02-1.40, P=0.002 ; I^{2}=29 \%\right)$ and the cut-off value $>150(\mathrm{HR}=1.39,95 \% \mathrm{CI}=1.23-1.56, P<0.00001$; $I^{2}=43 \%$ ). As for treatment, obvious association between the PLR and OS was detected not only when the treatment was surgery $\left(\mathrm{HR}=1.86,95 \% \mathrm{CI}=1.22-2.84, P=0.004 ; I^{2}=63 \%\right)$ but also when the treatment was not surgery $(\mathrm{HR}=1.24$, 95\% CI=1.13-1.36, $P<0.0001 ; I^{2}=22 \%$ ).

The further analysis was conducted based on the 7 studies assessed with multivariate analysis. As listed in Table 3,

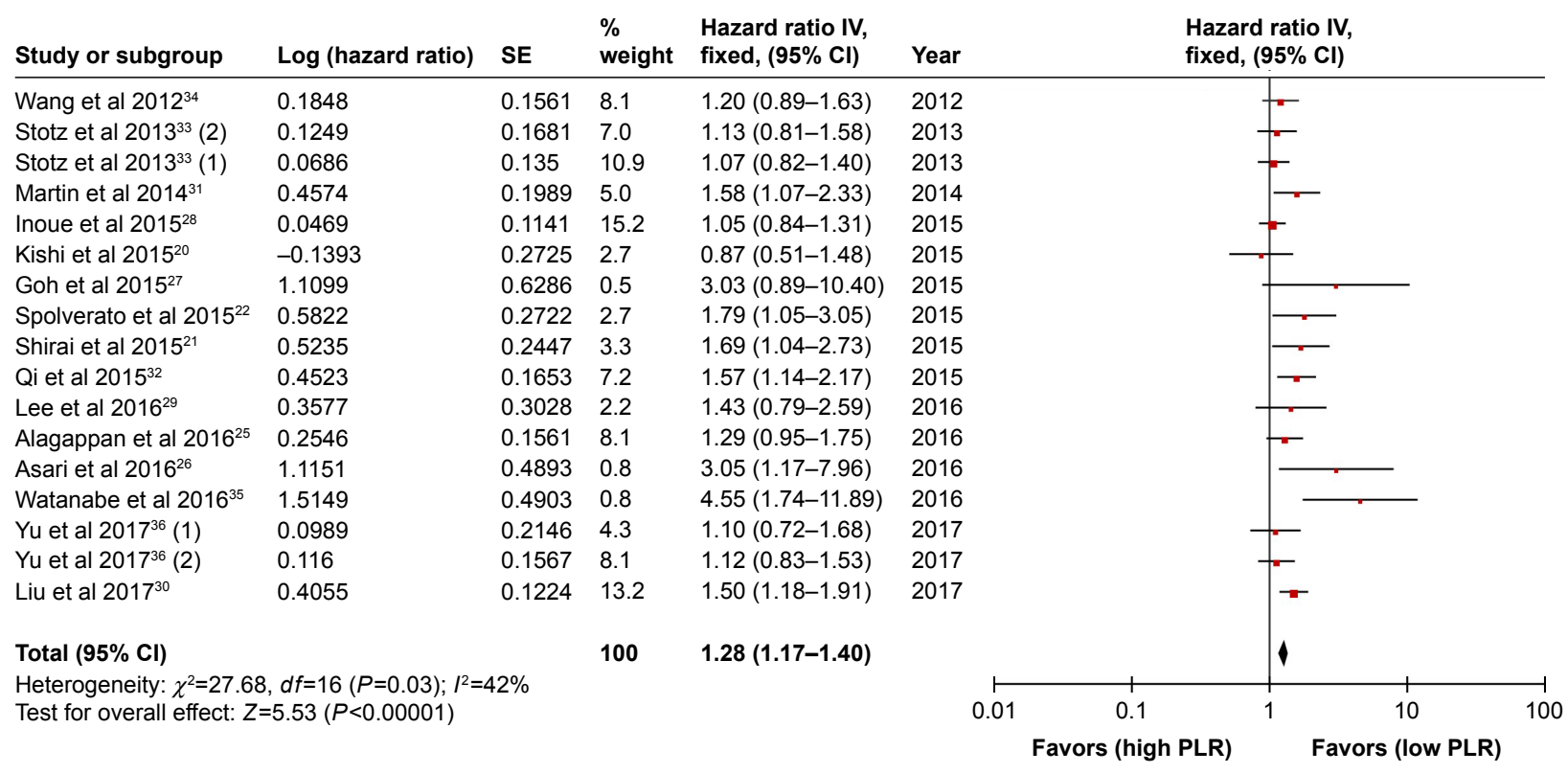

Figure 2 Meta-analysis of overall survival.

Abbreviations: $d f$, degrees of freedom; PLR, platelet-to-lymphocyte ratio; SE, standad error. 


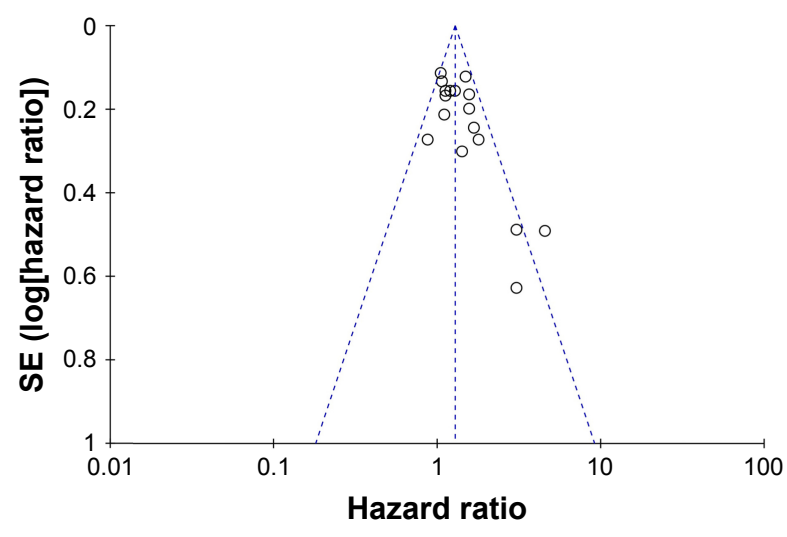

Figure 3 Funnel plot of overall survival.

Abbreviation: SE, standard error.

obvious relationship between the PLR and OS in pancreatic cancer was detected based on the subgroup analyses regarding the main adjusted potential confounders, including CA199, NLR, mGPS, albumin, CRP, ECOG, stage, tumor size, nodal involvement, tumor differentiation, margin status, age and gender.

\section{The meta-analysis of PFS}

Among the included studies, two studies reported the DFS, one study presented the RFS and one study covered the PFS. Also, these four studies were finally included into the metaanalysis of PFS. As shown in Figure 4, the results indicated that low PLR was significantly associated with longer PFS when compared to high PLR, with low heterogeneity $\left(\mathrm{HR}=1.27,95 \% \mathrm{CI}=1.03-1.57, P=0.03 ; I^{2}=33 \%\right)$. In addition, funnel plot indicated that there was no obvious bias of included studies (Figure 5).

\section{Discussion}

Inflammation is a hallmark of various cancers. Increasing evidences have shown that systemic inflammatory response was involved in tumorigenesis, malignant transformation and metastasis. ${ }^{37,38}$ Platelet has been proved to be associated with the diagnosis and treatment of cancers. ${ }^{39,40}$ Besides, lymphocyte infiltration in advanced stages is lower than that in the early stages of pancreatic cancer. In recent years, more and more researchers have started to pay attention to the prognostic role of PLR in various cancers, including liver cancer, ${ }^{41}$ lung cancer ${ }^{42}$ and colorectal cancer, ${ }^{43}$ as well as esophageal cancer. ${ }^{44}$ Similarly, the prognostic value of PLR in pancreatic cancer was also being investigated; however, the results were controversial. . $^{21,26,28,31}$

In the current study, the results demonstrated that PLR was significantly associated with the OS of patients with pancreatic cancer, which was similar to the conclusion in other cancers. ${ }^{42,44}{ }^{48}$ Patients with low PLR had longer OS when compared to the patients with high PLR, indicating that low PLR might be a protective factor for pancreatic cancer. Besides, the subgroup analysis based on analysis model, ethnicity, sample size and cut-off value also presented similar results. It is worth mentioning that we conducted further analysis based on the adjusted potential confounders, including CA199, NLR, mGPS, albumin, CRP, ECOG, stage, tumor size, nodal involvement, tumor differentiation, margin status, age and gender, which was not reported in the earlier similar meta-analysis. ${ }^{19,44}$ Also, the results confirmed that low PLR was associated with longer OS in pancreatic cancer. We further explored the association between PLR, PFS, RFS and DFS; the results similarly demonstrated that

Table 2 Subgroup analysis of the association between the PLR expression and OS

\begin{tabular}{|c|c|c|c|c|c|c|}
\hline $\begin{array}{l}\text { Survival } \\
\text { analysis }\end{array}$ & $\begin{array}{l}\text { Included } \\
\text { cohorts }\end{array}$ & HR (95\% CI) & $P$-value & $I^{2}(\%)$ & $\begin{array}{l}P \text {-value for } \\
\text { heterogeneity }\end{array}$ & $\begin{array}{l}\text { Analysis } \\
\text { model }\end{array}$ \\
\hline \multicolumn{7}{|l|}{ Analysis model } \\
\hline Multivariate & 7 & $1.76(1.45-2.14)$ & $<0.00001 *$ & 9 & 0.36 & Fixed \\
\hline Univariate & 10 & I.I8 (1.07-1.30) & $0.001 *$ & 0 & 0.57 & Fixed \\
\hline \multicolumn{7}{|l|}{ Ethnicity } \\
\hline Caucasian & 5 & $1.25(1.08-1.45)$ & $0.004^{*}$ & 17 & 0.31 & Fixed \\
\hline Asian & 12 & $1.35(1.14-1.61)$ & $0.0006 *$ & 52 & 0.02 & Random \\
\hline \multicolumn{7}{|l|}{ Sample size } \\
\hline$\leq 150$ & 9 & $1.49(1.14-1.94)$ & $0.003^{*}$ & 52 & 0.03 & Random \\
\hline$>150$ & 8 & $1.26(1.11-1.42)$ & $0.0003 *$ & 31 & 0.18 & Fixed \\
\hline \multicolumn{7}{|l|}{ Cut-off value } \\
\hline$\leq 150$ & 7 & $1.19(1.02-1.40)$ & $0.03 *$ & 29 & 0.21 & Fixed \\
\hline$>150$ & 10 & $1.39(1.23-1.56)$ & $<0.00001 *$ & 43 & 0.07 & Fixed \\
\hline \multicolumn{7}{|l|}{ Treatment } \\
\hline Surgery & 5 & $1.86(1.22-2.84)$ & $0.004^{*}$ & 63 & 0.029 & Random \\
\hline Not surgery & 12 & $1.24(1.13-1.36)$ & $<0.00001 *$ & 22 & 0.229 & Fixed \\
\hline
\end{tabular}

Note: $* P<0.05$, the difference was statistically significant.

Abbreviations: HR, hazard ratio; OS, overall survival; PLR, platelet-to-lymphocyte ratio. 
Table 3 Subgroup analysis of OS based on the adjusted potential confounders of the seven studies assessed with multivariate analysis

\begin{tabular}{|c|c|c|c|c|c|c|}
\hline Analysis & $\begin{array}{l}\text { Included } \\
\text { cohorts }\end{array}$ & HR $(95 \% \mathrm{CI})$ & $P$-value & $I^{2}(\%)$ & $\begin{array}{l}P \text {-value for } \\
\text { heterogeneity }\end{array}$ & Mode \\
\hline \multicolumn{7}{|l|}{ CAI9-9 } \\
\hline Yes & 3 & 1.64 (1.29-2.09) & $<0.000 I^{*}$ & 0 & 0.43 & Fixed \\
\hline No & 4 & $2.01(1.45-2.77)$ & $<0.0001 *$ & 23 & 0.27 & Fixed \\
\hline \multicolumn{7}{|l|}{ NLR } \\
\hline Yes & 6 & $1.88(1.48-2.39)$ & $<0.0000$ I* & 14 & 0.33 & Fixed \\
\hline No & I & $1.57(1.14-2.17)$ & $0.0006 *$ & NA & NA & Fixed \\
\hline \multicolumn{7}{|l|}{ mGPS } \\
\hline Yes & 2 & $1.73(1.21-2.49)$ & $0.003 *$ & 36 & 0.13 & Fixed \\
\hline No & 5 & $1.78(1.4 \mid-2.23)$ & $<0.000 I^{*}$ & 20 & 0.29 & Fixed \\
\hline \multicolumn{7}{|l|}{ Albumin } \\
\hline Yes & 2 & $1.73(1.21-2.49)$ & $0.003^{*}$ & 36 & 0.13 & Fixed \\
\hline No & 5 & $1.78(1.4 I-2.23)$ & $<0.000$ I* & 20 & 0.29 & Fixed \\
\hline \multicolumn{7}{|l|}{ CRP } \\
\hline Yes & I & $1.58(1.07-2.33)$ & $0.02 *$ & NA & NA & Fixed \\
\hline No & 6 & $1.83(1.46-2.29)$ & $<0.000$ I* & 19 & 0.29 & Fixed \\
\hline \multicolumn{7}{|c|}{ Tumor size } \\
\hline Yes & 2 & $1.73(1.21-2.48)$ & $0.005^{*}$ & 0 & 0.87 & Fixed \\
\hline No & 5 & $1.78(1.4 \mid-2.24)$ & $<0.0000$ I* & 39 & 0.16 & Fixed \\
\hline \multicolumn{7}{|l|}{ Gender } \\
\hline Yes & I & $1.79(1.05-3.05)$ & $0.03 *$ & NA & NA & Fixed \\
\hline No & 6 & $1.76(1.43-2.17)$ & $<0.000 I^{*}$ & 24 & 0.26 & Fixed \\
\hline \multicolumn{7}{|l|}{ ECOG } \\
\hline Yes & I & $1.58(1.07-2.33)$ & $0.02 *$ & NA & NA & Fixed \\
\hline No & 6 & $1.83(1.46-2.29)$ & $<0.000 I^{*}$ & 19 & 0.29 & Fixed \\
\hline \multicolumn{7}{|l|}{ Stage } \\
\hline Yes & I & $1.57(1.14-2.17)$ & $0.01 *$ & NA & NA & Fixed \\
\hline No & 6 & $1.88(1.48-2.39)$ & $<0.000 I^{*}$ & 14 & 0.33 & Fixed \\
\hline \multicolumn{7}{|c|}{ Nodal involvement } \\
\hline Yes & 2 & $1.73(1.21-2.48)$ & $0.003 *$ & 0 & 0.87 & Fixed \\
\hline No & 5 & $1.78(1.41-2.24)$ & $<0.00001$ & 39 & 0.16 & Fixed \\
\hline \multicolumn{7}{|l|}{ Albumin } \\
\hline Yes & 2 & $1.73(1.21-2.49)$ & $0.003 *$ & 36 & 0.13 & Fixed \\
\hline No & 5 & $1.78(1.4 \mid-2.23)$ & $<0.0001$ & 20 & 0.29 & Fixed \\
\hline \multicolumn{7}{|c|}{ Margin status } \\
\hline Yes & 3 & $1.86(1.33-2.59)$ & $0.0003 *$ & 0 & 0.55 & Fixed \\
\hline No & 4 & $1.72(1.36-2.18)$ & $<0.0000 I^{*}$ & 43 & 0.61 & Fixed \\
\hline \multicolumn{7}{|c|}{ Tumor differentiation } \\
\hline Yes & I & $1.69(1.04-2.73)$ & $0.03 *$ & NA & NA & Fixed \\
\hline No & 6 & $1.78(1.44-2.20)$ & $<0.0000 I^{*}$ & 23 & 0.26 & Fixed \\
\hline \multicolumn{7}{|l|}{ Age } \\
\hline Yes & I & $1.79(1.05-3.05)$ & $0.03 *$ & NA & NA & Fixed \\
\hline No & 6 & $1.76(1.43-2.17)$ & $<0.000 I^{*}$ & 24 & 0.26 & Fixed \\
\hline
\end{tabular}

Note: $* P<0.05$, the difference was statistically significant.

Abbreviations: CRP, C-reactive protein; ECOG, Eastern Cooperative Oncology Group; HR, hazard ratio; mGPS, modified Glasgow Prognostic Score; NA, not available; NLR, neutrophil-to-lymphocyte ratio; OS, overall survival.

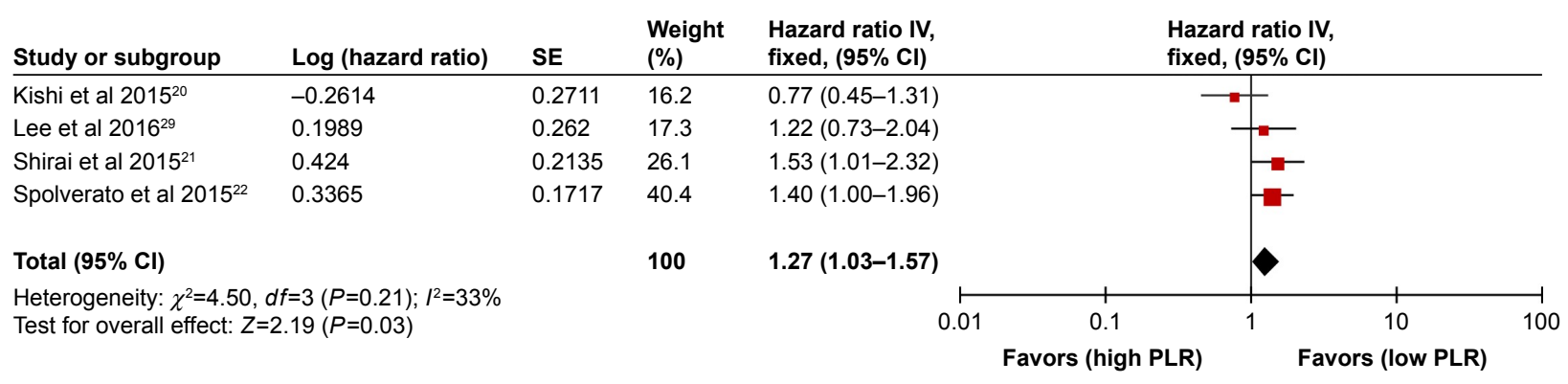

Figure 4 Meta-analysis of progression-free survival.

Abbreviations: $\mathrm{df}$, degrees of freedom; PLR, platelet-to-lymphocyte ratio; SE, standard error. 


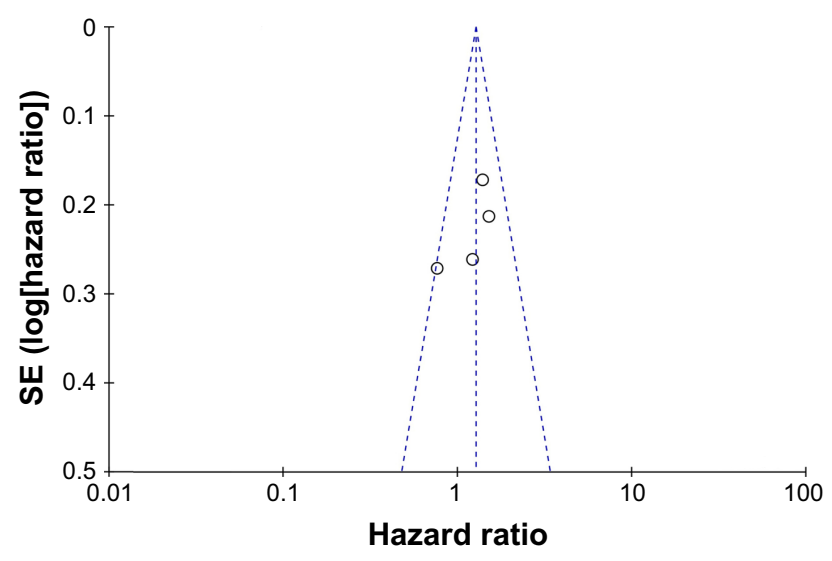

Figure 5 Funnel plot of progression-free survival. Abbreviation: SE, standard error.

low PLR was a protective factor for patients with pancreatic cancer. Zhou et al performed a meta-analysis to explore the prognostic value of PLR in various cancers and found that PLR was not associated with OS in pancreatic cancer, which was inconsistent with our study. ${ }^{49}$ It should be noted that only three studies were included in the meta-analysis of OS in Zhou et al's study. ${ }^{49}$ Nevertheless, 17 cohort studies were finally included in the meta-analysis of OS; therefore, our conclusion was more convincing.

In spite of the conclusion arrived at in our study, the underlining mechanism of the prognostic value of PLR in pancreatic cancer remains unclear. Platelets might promote tumor growth, angiogenesis, metastasis and cancerassociated thrombosis. ${ }^{50,51}$ Moreover, Abiko et al reported that interferon-gamma from the lymphocytes induced PD-L1 expression and promoted the progression of ovarian cancer. ${ }^{52}$ Besides, He et al declared that lymphocyte promoted tumorigenesis by activating gene-3, an important immune checkpoint in cancer. ${ }^{53} \mathrm{Xu}$ et al found that circulating CD3+CD8+ $\mathrm{T}$ lymphocytes might be used as a prognostic biomarker for lung cancer. ${ }^{54}$ Based on the platelet and lymphocyte counts, PLR might be related to the prognosis of patients with pancreatic cancer.

To the best of our knowledge, this is the first metaanalysis to explore the prognostic value of PLR in pancreatic cancer. Besides, our study contained 17 cohort studies involving 3,182 patients; therefore, the conclusion was convincing. Nonetheless, our meta-analysis is not without any limitation. First, all the data were obtained from the published articles and the original data of included patients were unavailable. Second, patients in the meta-analysis received several therapies and we cannot get the details, which may lower the applicability of this study. Third, the cut-off value of the included studies varied a lot, which might increase the heterogeneity. Fourth, some included studies lacked assessment of the confounding factors.

\section{Conclusion}

PLR could be used as a prognostic predictor in patients with pancreatic cancer. High PLR was associated with poor prognosis, especially shorter OS. In contrast, low PLR obviously was correlated with favorable OS in pancreatic cancer. More studies should be carried out to investigate the underlying mechanism.

\section{Author contributions}

Study concepts and design: YZZ, HXQ, YPZ; literature search: YPZ, SJC; data extraction: YZZ, YPZ; manuscript preparation and revision: AHF, SJC, YPZ, HXQ. All authors have participated sufficiently in the study and approved the final version. All authors contributed toward data analysis, drafting and revising the paper and agree to be accountable for all aspects of the work.

\section{Disclosure}

The authors report no conflicts of interest in this work.

\section{References}

1. Siegel RL, Miller KD, Jemal A. Cancer statistics, 2017. CA Cancer J Clin. 2017;67:7-30.

2. Ilic M, Ilic I. Epidemiology of pancreatic cancer. World J Gastroenterol. 2016;22:9694-9705.

3. Kamisawa T, Wood LD, Itoi T, Takaori K. Pancreatic cancer. Lancet. 2016;388:73-85.

4. Siegel RL, Miller KD, Jemal A. Cancer statistics, 2016. CA Cancer J Clin. 2016;66:7-30.

5. Huang J, Zhao Y, Xu Y, et al. Comparative effectiveness and safety between oxaliplatin-based and cisplatin-based therapy in advanced gastric cancer: a meta-analysis of randomized controlled trials. Oncotarget. 2016;7:34824-34831.

6. Wang J, Zhao Y, Qi R, et al. Prognostic role of podocalyxin-like protein expression in various cancers: a systematic review and meta-analysis. Oncotarget. 2016;8(32):52457-52464.

7. Zhao Y, Si G, Zhu F, et al. Prognostic role of platelet to lymphocyte ratio in hepatocellular carcinoma: a systematic review and meta-analysis. Oncotarget. 2017;8:22854-22862.

8. Zhao Y, Wang H, Shi Y, et al. Comparative effectiveness of combined therapy inhibiting EGFR and VEGF pathways in patients with advanced non-small-cell lung cancer: a meta-analysis of 16 phase II/III randomized trials. Oncotarget. 2017;8:7014-7024.

9. Cheng H, Luo G, Lu Y, et al. The combination of systemic inflammation-based marker NLR and circulating regulatory T cells predicts the prognosis of resectable pancreatic cancer patients. Pancreatology. 2016;16:1080-1084.

10. Leppanen J, Helminen O, Huhta H, et al. High toll-like receptor (TLR) 9 expression is associated with better prognosis in surgically treated pancreatic cancer patients. Virchows Arch. 2017;470:401-410.

11. Li BS, Liu H, Yang WL. Reduced miRNA-218 expression in pancreatic cancer patients as a predictor of poor prognosis. Genet Mol Res. 2015; 14:16372-16378. 
12. Zhang Y, Jiang H, Qin M, Su X, Cao Z, Wang J. TNIK serves as a novel biomarker associated with poor prognosis in patients with pancreatic cancer. Tumour Biol. 2016;37:1035-1040.

13. Dai D, Zhang CF, Williams S, Yuan CS, Wang CZ. Ginseng on cancer: potential role in modulating inflammation-mediated angiogenesis. Am J Chin Med. 2017;45:13-22.

14. Hung RJ, Ulrich CM, Goode EL, et al. Cross cancer genomic investigation of inflammation pathway for five common cancers: lung, ovary, prostate, breast, and colorectal cancer. J Natl Cancer Inst. 2015;107.

15. Kimura Y, Nagai N, Tsunekawa N, et al. IL-17A-producing CD30(+) Vdelta1 T cells drive inflammation-induced cancer progression. Cancer Sci. 2016;107:1206-1214.

16. Shigdar S, Li Y, Bhattacharya S, et al. Inflammation and cancer stem cells. Cancer Lett. 2014;345:271-278.

17. Asaoka T, Miyamoto A, Maeda S, et al. Prognostic impact of preoperative NLR and CA19-9 in pancreatic cancer. Pancreatology. 2016;16:434 440.

18. Stevens L, Pathak S, Nunes QM, et al. Prognostic significance of preoperative C-reactive protein and the neutrophil-lymphocyte ratio in resectable pancreatic cancer: a systematic review. HPB (Oxford). 2015; 17:285-291.

19. Yang JJ, Hu ZG, Shi WX, Deng T, He SQ, Yuan SG. Prognostic significance of neutrophil to lymphocyte ratio in pancreatic cancer: a meta-analysis. World J Gastroenterol. 2015;21:2807-2815.

20. Kishi T, Nakamura A, Itasaka S, et al. Pretreatment C-reactive protein level predicts outcome and patterns of failure after chemoradiotherapy for locally advanced pancreatic cancer. Pancreatology. 2015; 15:694-700.

21. Shirai Y, Shiba H, Sakamoto T, et al. Preoperative platelet to lymphocyte ratio predicts outcome of patients with pancreatic ductal adenocarcinoma after pancreatic resection. Surgery. 2015;158:360-365.

22. Spolverato G, Maqsood H, Kim Y, et al. Neutrophil-lymphocyte and platelet-lymphocyte ratio in patients after resection for hepatopancreatico-biliary malignancies. J Surg Oncol. 2015;111:868-874.

23. Tierney JF, Stewart LA, Ghersi D, Burdett S, Sydes MR. Practical methods for incorporating summary time-to-event data into metaanalysis. Trials. 2007;8:16.

24. Liberati A, Altman DG, Tetzlaff J, et al. The PRISMA statement for reporting systematic reviews and meta-analyses of studies that evaluate health care interventions: explanation and elaboration. PLoS Med. 2009;6:e1000100.

25. Alagappan M, Pollom EL, von Eyben R, et al. Albumin and neutrophillymphocyte ratio (NLR) predict survival in patients with pancreatic adenocarcinoma treated with SBRT. Am J Clin Oncol. Epub 2016 Jan 13.

26. Asari S, Matsumoto I, Toyama H, et al. Preoperative independent prognostic factors in patients with borderline resectable pancreatic ductal adenocarcinoma following curative resection: the neutrophil-lymphocyte and platelet-lymphocyte ratios. Surg Today. 2016;46:583-592.

27. Goh BK, Tan DM, Chan CY, et al. Are preoperative blood neutrophilto-lymphocyte and platelet-to-lymphocyte ratios useful in predicting malignancy in surgically-treated mucin-producing pancreatic cystic neoplasms? J Surg Oncol. 2015;112:366-371.

28. Inoue D, Ozaka M, Matsuyama M, et al. Prognostic value of neutrophillymphocyte ratio and level of C-reactive protein in a large cohort of pancreatic cancer patients: a retrospective study in a single institute in Japan. Jpn J Clin Oncol. 2015;45:61-66.

29. Lee JM, Lee HS, Hyun JJ, et al. Prognostic value of inflammation-based markers in patients with pancreatic cancer administered gemcitabine and erlotinib. World J Gastrointest Oncol. 2016;8:555-562.

30. Liu Z, Jin K, Guo M, et al. Prognostic value of the CRP/Alb ratio, a novel inflammation-based score in pancreatic cancer. Ann Surg Oncol. 2017; 24:561-568.

31. Martin HL, Ohara K, Kiberu A, et al. Prognostic value of systemic inflammation-based markers in advanced pancreatic cancer. Intern Med J. 2014;44:676-682.

32. Qi Q, Geng Y, Sun M, Wang P, Chen Z. Clinical implications of systemic inflammatory response markers as independent prognostic factors for advanced pancreatic cancer. Pancreatology. 2015;15:145-150.
33. Stotz M, Gerger A, Eisner F, et al. Increased neutrophil-lymphocyte ratio is a poor prognostic factor in patients with primary operable and inoperable pancreatic cancer. Br J Cancer. 2013;109:416-421.

34. Wang DS, Luo HY, Qiu MZ, et al. Comparison of the prognostic values of various inflammation based factors in patients with pancreatic cancer. Med Oncol. 2012;29:3092-3100.

35. Watanabe J, Otani S, Sakamoto T, et al. Prognostic indicators based on inflammatory and nutritional factors after pancreaticoduodenectomy for pancreatic cancer. Surg Today. 2016;46:1258-1267.

36. Yu SL, Xu LT, Qi Q, et al. Serum lactate dehydrogenase predicts prognosis and correlates with systemic inflammatory response in patients with advanced pancreatic cancer after gemcitabine-based chemotherapy. Sci Rep. 2017;7:45194.

37. Hanahan D, Weinberg RA. Hallmarks of cancer: the next generation. Cell. 2011;144:646-674.

38. Munkley J, Elliott DJ. Hallmarks of glycosylation in cancer. Oncotarget. 2016; 7:35478-35489.

39. Hanze J, Jakubowski P, Heers H, et al. Assessing blood platelets as RNA biomarker source for prostate cancer. Biomarkers. 2016;21:653-659.

40. Holmes CE, Levis JE, Schneider DJ, et al. Platelet phenotype changes associated with breast cancer and its treatment. Platelets. 2016;27: 703-711.

41. Ma W, Zhang P, Qi J, et al. Prognostic value of platelet to lymphocyte ratio in hepatocellular carcinoma: a meta-analysis. Sci Rep. 2016;6: 35378.

42. Ding N, Pang Z, Shen H, Ni Y, Du J, Liu Q. The prognostic value of PLR in lung cancer, a meta-analysis based on results from a large consecutive cohort. Sci Rep. 2016;6:34823.

43. Chen N, Li W, Huang K, et al. Increased platelet-lymphocyte ratio closely relates to inferior clinical features and worse long-term survival in both resected and metastatic colorectal cancer: an updated systematic review and meta-analysis of 24 studies. Oncotarget. 2017;8(19): 32356-32369.

44. Yodying H, Matsuda A, Miyashita M, et al. Prognostic significance of neutrophil-to-lymphocyte ratio and platelet-to-lymphocyte ratio in oncologic outcomes of esophageal cancer: a systematic review and meta-analysis. Ann Surg Oncol. 2016;23:646-654.

45. Qiang G, Liang C, Xiao F, et al. Prognostic significance of platelet-tolymphocyte ratio in non-small-cell lung cancer: a meta-analysis. Onco Targets Ther. 2016;9:869-876.

46. Tan D, Fu Y, Su Q, Wang H. Prognostic role of platelet-lymphocyte ratio in colorectal cancer: a systematic review and meta-analysis. Medicine (Baltimore). 2016;95:e3837.

47. Zhang H, Gao L, Zhang B, Zhang L, Wang C. Prognostic value of platelet to lymphocyte ratio in non-small cell lung cancer: a systematic review and meta-analysis. Sci Rep. 2016;6:22618.

48. Zhao QT, Yuan Z, Zhang H, et al. Prognostic role of platelet to lymphocyte ratio in non-small cell lung cancers: a meta-analysis including 3,720 patients. Int J Cancer. 2016;139:164-170.

49. Zhou X, Du Y, Huang Z, et al. Prognostic value of PLR in various cancers: a meta-analysis. PLoS One. 2014;9:e101119.

50. Mezouar S, Frere C, Darbousset R, et al. Role of platelets in cancer and cancer-associated thrombosis: experimental and clinical evidences. Thromb Res. 2016;139:65-76.

51. Menter DG, Tucker SC, Kopetz S, et al. Platelets and cancer: a casual or causal relationship: revisited. Cancer Metastasis Rev. 2014;33: 231-269.

52. Abiko K, Matsumura N, Hamanishi J, et al. IFN-gamma from lymphocytes induces PD-L1 expression and promotes progression of ovarian cancer. Br J Cancer. 2015;112:1501-1509.

53. He Y, Rivard CJ, Rozeboom L, et al. Lymphocyte-activation gene-3, an important immune checkpoint in cancer. Cancer Sci. 2016;107: 1193-1197.

54. $\mathrm{Xu} \mathrm{L}$, Chen D, Lu C, et al. Advanced lung cancer is associated with decreased expression of perforin, CD95, CD38 by circulating CD3+CD8+ T lymphocytes. Ann Clin Lab Sci. 2015;45:528-532. 


\section{Supplementary materials}

Table SI Adjustment for potential confounders of the seven included studies assessed with multivariate analysis

\begin{tabular}{|c|c|c|c|c|c|c|c|c|c|c|c|c|c|}
\hline Study & CAI99 & NLR & mGPS & Albumin & CRP & ECOG & Stage & $\begin{array}{l}\text { Tumor } \\
\text { size }\end{array}$ & $\begin{array}{l}\text { Nodal } \\
\text { involvement }\end{array}$ & $\begin{array}{l}\text { Margin } \\
\text { status }\end{array}$ & $\begin{array}{l}\text { Tumor } \\
\text { differentiation }\end{array}$ & Age & Gender \\
\hline Martin et al $2014^{10}$ & $\sqrt{ }$ & $\sqrt{ }$ & $\sqrt{ }$ & $\sqrt{ }$ & $\sqrt{ }$ & $\sqrt{ }$ & & & & & & & \\
\hline Qi et al 2015"I & $\sqrt{ }$ & & & & & & $\sqrt{ }$ & & & & & & \\
\hline Goh et al $2015^{6}$ & & $\sqrt{ }$ & & & & & & & & & & & \\
\hline Shirai et al $2015^{2}$ & & $\sqrt{ }$ & & & & & & $\sqrt{ }$ & $\sqrt{ }$ & $\sqrt{ }$ & $\sqrt{ }$ & & \\
\hline $\begin{array}{l}\text { Spolverato et al } \\
2015^{3}\end{array}$ & & $\sqrt{ }$ & & & & & & $\sqrt{ }$ & $\sqrt{ }$ & $\sqrt{ }$ & & $\sqrt{ }$ & $\sqrt{ }$ \\
\hline $\begin{array}{l}\text { Asari et al } 2016^{5} \\
\text { Watanabe et al } \\
2016^{14}\end{array}$ & $\sqrt{ }$ & $\begin{array}{l}\sqrt{ } \\
\sqrt{ }\end{array}$ & $\sqrt{ }$ & $\sqrt{ }$ & & & & & & $\sqrt{ }$ & & & \\
\hline
\end{tabular}

Abbreviations: CRP, C-reactive protein; ECOG, Eastern Cooperative Oncology Group; mGPS, modified Glasgow Prognostic Score; NLR, neutrophil-to-lymphocyte ratio.

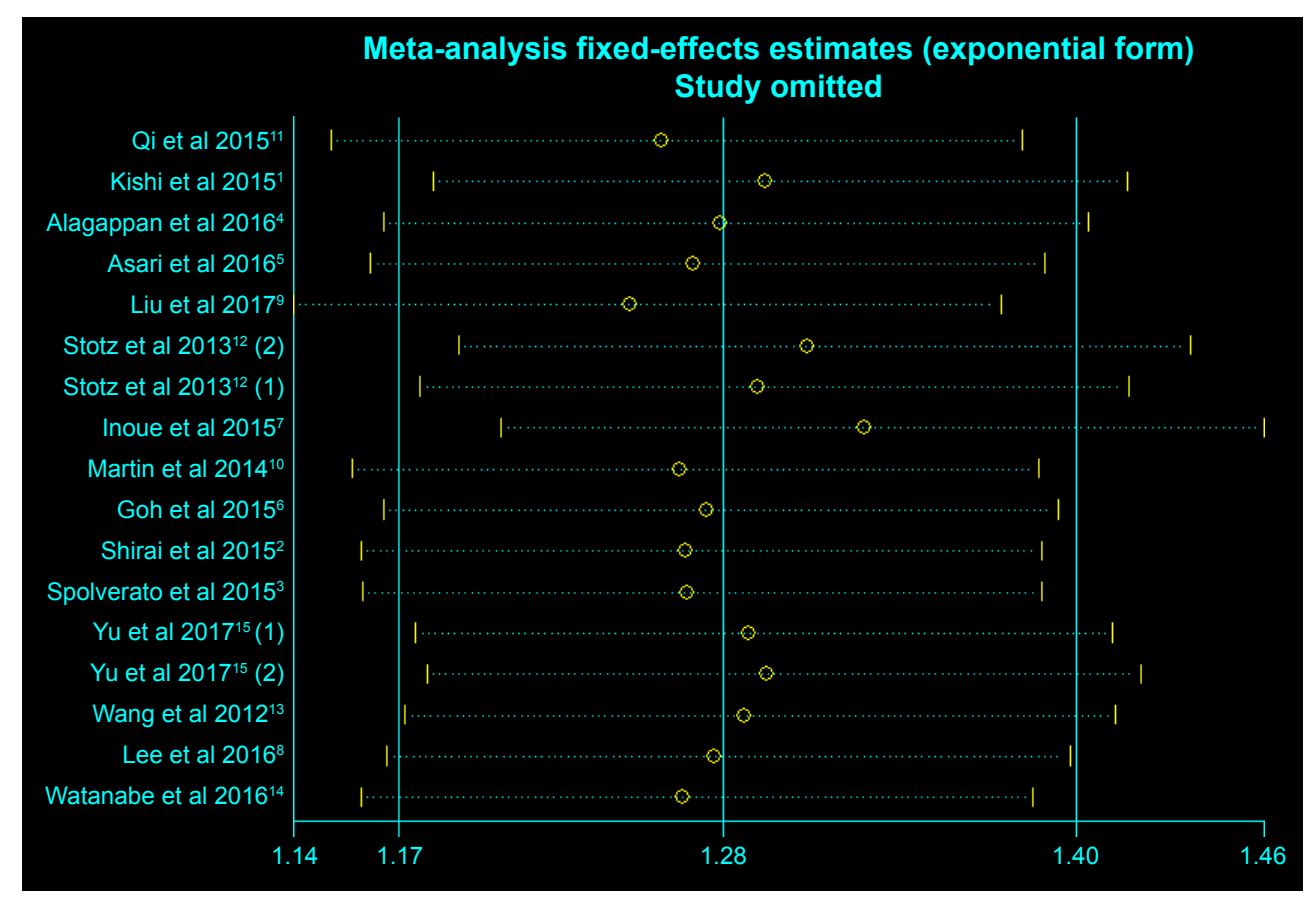

Figure SI Sensitivity analysis of overall survival.

Note: (I) cohort I; (2) cohort II.

\section{References}

1. Kishi T, Nakamura A, Itasaka S, et al. Pretreatment C-reactive protein level predicts outcome and patterns of failure after chemoradiotherapy for locally advanced pancreatic cancer. Pancreatology. 2015;15: 694-700.

2. Shirai Y, Shiba H, Sakamoto T, et al. Preoperative platelet to lymphocyte ratio predicts outcome of patients with pancreatic ductal adenocarcinoma after pancreatic resection. Surgery. 2015;158:360-365.

3. Spolverato G, Maqsood H, Kim Y, et al. Neutrophil-lymphocyte and platelet-lymphocyte ratio in patients after resection for hepato-pancreatico-biliary malignancies. $J$ Surg Oncol. 2015;111:868-874.

4. Alagappan M, Pollom EL, von Eyben R, et al. Albumin and neutrophillymphocyte ratio (NLR) predict survival in patients with pancreatic adenocarcinoma treated with SBRT. Am J Clin Oncol. Epub 2016 Jan 13.
5. Asari S, Matsumoto I, Toyama H, et al. Preoperative independent prognostic factors in patients with borderline resectable pancreatic ductal adenocarcinoma following curative resection: the neutrophillymphocyte and platelet-lymphocyte ratios. Surg Today. 2016;46: 583-592.

6. Goh BK, Tan DM, Chan CY, et al. Are preoperative blood neutrophilto-lymphocyte and platelet-to-lymphocyte ratios useful in predicting malignancy in surgically-treated mucin-producing pancreatic cystic neoplasms? J Surg Oncol. 2015;112:366-371.

7. Inoue D, Ozaka M, Matsuyama M, et al. Prognostic value of neutrophillymphocyte ratio and level of C-reactive protein in a large cohort of pancreatic cancer patients: a retrospective study in a single institute in Japan. Jpn J Clin Oncol. 2015;45:61-66.

8. Lee JM, Lee HS, Hyun JJ, et al. Prognostic value of inflammation-based markers in patients with pancreatic cancer administered gemcitabine and erlotinib. World J Gastrointest Oncol. 2016;8:555-562. 
9. Liu Z, Jin $\mathrm{K}$, Guo M, et al. Prognostic value of the CRP/Alb ratio, a novel inflammation-based score in pancreatic cancer. Ann Surg Oncol. 2017;24:561-568.

10. Martin HL, Ohara K, Kiberu A, et al. Prognostic value of systemic inflammation-based markers in advanced pancreatic cancer. Intern Med J. 2014;44:676-682.

11. Qi Q, Geng Y, Sun M, Wang P, Chen Z. Clinical implications of systemic inflammatory response markers as independent prognostic factors for advanced pancreatic cancer. Pancreatology. 2015;15: $145-150$.

12. Stotz M, Gerger A, Eisner F, et al. Increased neutrophil-lymphocyte ratio is a poor prognostic factor in patients with primary operable and inoperable pancreatic cancer. Br J Cancer. 2013;109:416-421.
13. Wang DS, Luo HY, Qiu MZ, et al. Comparison of the prognostic values of various inflammation based factors in patients with pancreatic cancer. Med Oncol. 2012;29:3092-3100.

14. Watanabe J, Otani S, Sakamoto T, et al. Prognostic indicators based on inflammatory and nutritional factors after pancreaticoduodenectomy for pancreatic cancer. Surg Today. 2016;46:1258-1267. 21. Shirai Y, Shiba H, Sakamoto T, et al. Preoperative platelet to lymphocyte ratio predicts outcome of patients with pancreatic ductal adenocarcinoma after pancreatic resection. Surgery. 2015;158:360-365.

15. Yu SL, Xu LT, Qi Q, et al. Serum lactate dehydrogenase predicts prognosis and correlates with systemic inflammatory response in patients with advanced pancreatic cancer after gemcitabine-based chemotherapy. Sci Rep. 2017;7:45194.

\section{Publish your work in this journal}

OncoTargets and Therapy is an international, peer-reviewed, open access journal focusing on the pathological basis of all cancers, potential targets for therapy and treatment protocols employed to improve the management of cancer patients. The journal also focuses on the impact of management programs and new therapeutic agents and protocols on

\section{Dovepress}

patient perspectives such as quality of life, adherence and satisfaction. The manuscript management system is completely online and includes a very quick and fair peer-review system, which is all easy to use. Visit http://www.dovepress.com/testimonials.php to read real quotes from published authors. 